\title{
ECG record during changes in oesophageal $\mathrm{pH}$
}

\author{
$M$ Wani and S Hishon
}

\begin{abstract}
Seventeen patients with non-cardiac chest pain were investigated by simultaneous ambulatory 24 hour ECG and oesophageal pH monitoring. While 11 patients lowered their oesophageal pH below 4 for a significant percentage, $(3.4 \%)$ of recorded time and experienced chest pain, no simultaneous ECG changes occurred. In 10 patients chest pain was reproduced by an oesophageal acid perfusion test (Bernstein test). No changes in ECG record during the test were shown. We conclude that although reflux oesophageal pain may be difficult to differentiate from cardiac pain, clinically oesophageal pH changes do not produce any ECG changes.
\end{abstract}

Oesophageal pain is the commonest cause of non-cardiac chest pain ${ }^{12}$ and is often difficult to clinically differentiate from true cardiac angina.

Low oesophageal $\mathrm{pH}$ is a well established cause of angina like pain, as has been shown by acid perfusion studies in the past and more recently by 24 hour ambulatory oesophageal pH monitoring. ${ }^{34}$ The common innervation between oesophagus and cardiac structures is a probable explanation.

Although low oesophageal pH can lower the threshold for true angina, ${ }^{5}$ it is not known whether a change in oesophageal $\mathrm{pH}$ can produce changes in the ECG. The aim of this study was to investigate this aspect.

\section{Methods}

PATIENTS

The subjects were selected from patients attending a general medicine outpatients department or admitted as emergencies with chest pain. Eleven men and six women aged from 33 and 63 years were included and the study was approved by the local Ethical Committee.

All patients had a careful history taken, clinical examination, and resting ECG performed. The characteristics of chest pain in this group of patients did not clearly point to its origin Patients admitted as emergencies with a suspected diagnosis of myocardial infarction had three serial ECGs and cardiac enzymes carried out. After excluding a cardiac cause on these grounds all patients were put through a standard (modified Bruce's protocol) exercise ECG test. Other cardiac investigations included a chest $x$-ray, echocardiogram and when indicated, coronary angiogram. Patients with a normal exercise test and some with symptomatically positive test had an upper gastrointestinal endoscopy performed before simultaneous ambulatory oesophageal pH and ECG monitoring ${ }^{678}$ which was performed over a period of 24 hours using the Novo Memolog $600 \mathrm{pH}$ electrode system and a Tracker 2 channel ECG monitor with Autosurveyor model SAl ECG analyser (Reynolds Medical Ltd). Patients were prescribed a standard diet during the monitoring period and supplied with diary cards on which the time of onset, duration, and character of symptoms were recorded.

Ten subjects agreed to have an oesophageal perfusion test. ${ }^{9}$ A nasogastric tube with its opening at $30 \mathrm{~cm}$ from the teeth was positioned in the oesophagus. The other end of the tube was attached to reservoirs of normal saline, $0 \cdot 1 \mathrm{~N}$ hydrochloric acid and sodium bicarbonate through a fourway stopcock arrangement which allowed rapid change from one solution to another without the patient's knowledge. The patient was instructed to indicate whether or not the infusion of a solution produced chest pain. With the patient sitting upright, normal saline was infused for five minutes at a rate of 100-120 drops per minute. The flow was switched to $0 \cdot 1$ $\mathrm{HC}$ and at the same rate until symptoms appeared or until 30 minutes. If the patient's usual symptoms were reproduced, the drip was changed to sodium bicarbonate. If the symptoms subsided, the effect of redripping with acid was observed. During the whole test ECG was monitored on a standard exercise monitor, using 12 channels and changes, if any, were recorded.

\section{Results}

The duration of symptoms at presentation ranged from three to 36 months. One patient had symptoms for six years. Except for one patient who was in intermittent atrial fibrillation, all patients had normal ECGs at rest. The time spent on treadmill ranged from four to 14 minutes. The end point was either a chest pain or achievement of $85 \%$ of predicted maximal heart rate for age. Two patients who had symptomatically positive exercise tests (at four and five minutes), were referred for coronary angiography which did not reveal any abnormality. Upper gastrointestinal endoscopy showed mild oesophagitis in six patients (including the two patients with positive exercise tests and normal coronary angiography). One patient has diffuse 
oesophagitis, gastritis, and duodenitis. In the other 10 patients no abnormality was found.

Apart from four patients, all had significant $(>3.4 \%$ time spent below $\mathrm{pH} 4)$ and symptomatic oesophageal reflux on 24 hour $\mathrm{pH}$ monitoring. (Range $3 \cdot 7 \%-50 \cdot 5 \%$.) Except for two patients none of the simultaneous ECG recordings showed any changes in ST segments. The ST segment changes in these two patients were asymptomatic and not related to any oesophageal $\mathrm{pH}$ changes. All the 10 patients who participated had positive Bernstein tests. In one patient (who also had ECG changes during ambulatory ECG and $\mathrm{pH}$ monitoring) ST segments significantly dropped during the Bernstein test. As this episode was associated with fast atrial fibrillation, however, a simple relation to low oesophageal $\mathrm{pH}$ cannot be established with confidence.

\section{Discussion}

The oesophagus may be the origin of chest pain clinically indistinguishable from that of ischaemic heart disease. Both motility and reflux disorders of the oesophagus could cause chest pain on their own or contribute to symptoms in patients in ischaemic heart disease. ${ }^{10}$ Maas et al developed an ambulatory manometry system in the diagnosis of oesophageal motor disorders causing chest pain." Angina like chest pains associated with ECG changes have been produced pharmacologically. ${ }^{10}$ Our aim was to investigate gastro-oesophageal reflux and its relation to ECG. Ambulatory 24 hour oesophageal $\mathrm{pH}$ monitoring is a very useful investigation in the diagnosis of chest pain. Two Italian studies have already shown the value of combined ambulatory 24 hour ECG and oesophageal pH monitoring in the investigation of non-cardiac chest pain. ${ }^{67}$ We have asked whether a change in the oesophageal $\mathrm{pH}$ can give rise to ECG changes and thus confuse the diagnosis. Our study showed no ECG changes during low oesophageal $\mathrm{pH}$ when such subjects experienced pain. Even deliberate lowering of oesophageal $\mathrm{pH}$ failed to induce any change in the ECG, although a reduction in oesophageal $\mathrm{pH}$ in patients with ischaemic heart disease is known to lower the threshold for angina and may even induce ECG changes. ${ }^{5}$ Two of our patients did manifest ST segment changes consistent with silent myocardial ischaemia. As these episodes did not have any relation to oesophageal $\mathrm{pH}$ changes and as no such changes were induced by Bernstein test, these changes should be ignored in this context. Further, the significance of silent myocardial ischaemia as manifested by ST segment changes in patients without known ischaemic heart disease is not very well established. ${ }^{12} 13$

We conclude that oesophageal $\mathrm{pH}$ changes do not cause ECG changes and either change observed during combined recording in a patient without known ischaemic heart disease should be interpreted as the sole cause of chest pain. There are situations, however, when ischaemic heart disease and oesophageal disorders coexist in the same patient. ${ }^{510}$ Ambulatory monitoring of the oesophagus ( $\mathrm{pH}$, pressure, or both) and ECG could significantly contribute to the management of such patient.

1 Richter, JE, Castell DO. Oesophageal disease as a cause of non-cardiac chest pain Adv Intern Med 1988; 0-A: 311-66. Caestecher JS de, Brown J, Blackwell JN, Heading RC. The oesophagus as a cause of recurrent chest pain: Which oesophagus as a cause of recurrent chest pain: Which patients should be investigated

3 Janssens J, Vantrappen G, Chillebert G. 24 hour recording of oesophageal pressure and $\mathrm{pH}$ in patients with non-cardiac chest pain. Gastroenterology: 1986; 90: 1978-84

4 Falor WM, Miller J, Kreus J, Jennin S, Greeczanik V, Crocker $\mathrm{N}$, Taylor B. 24 hour monitoring of oesophagopharyngea pH - out-patients $\mathcal{f}$ Thoracic Cardiovasc Surg 1986; 91 : $716-22$.

5 Davies HA et al. Oesophageal stimulation lowers exertional angina threshold. Lancet: 1985 ; i: $1011-4$.

6 Torref BE et al. Chest pain: Usefulness of associated dynamic electrocardiography and oesophageal $\mathrm{pH}$ monitoring. G Ital Cardiol 1984; 14: 982-9.

7 Marianeschi P et al. 24 your pH measurement and Holter ECG study in patients with non-cardiac angina. Minerva Med: 1986; 77: 787-92.

8 Demeester TR, Wang CI et al. Technique, indication and clinical use of 24 hour oesophageal $\mathrm{pH}$ monitoring. 7 Thoracic Cardiovasc Surg 1986; 79: 656-70.

9 Pope II CE. Bernstein test. Gastrointestinal Disease 1983; (4-7) 10 Lee MG et al. Chest pain - oesophageal, cardiac, or both? Am $\mathscr{F}$ Gastroenterol 1985; 8: $320-4$.

11 Maas LG et al. 24-hour ambulatory manometry in diagnosis of oesophageal motor disorders causing chest pain. South Med f 1985; 7: 810-38.

12 Crawford $\mathrm{M}$ et al. Limitations of continuous ambulatory ECG monitoring for detecting coronary artery disease. Ann Intern Med 1978; 89: 1-5.

13 Cecchi AC et al. Silent myocardial ischaemia during ambulatory ECG monitoring in patients with effort angina. $\mathcal{F} \mathrm{Am}$ Coll Cardiol 1983; 1: 934-9.

We would like to thank Mark Harvey and David Hartell for their technical assistance, and Heidi Staples and Carole Jones for their secretarial help. 